Editorial

\title{
How do you diagnosis and manage sports-related concussion (SRC) in elite road cycling? A Plan for developing SRC-assessment and management protocols within road cycling
}

\author{
Neil Heron ${ }^{1,2}$ \\ ${ }^{1}$ General Practice/Centre for Public Health, Queen's University Belfast, Belfast, UK \\ ${ }^{2}$ Department of General Practice, Keele University, Keele, Staffordshire, United Kingdom
}

* Correspondence: Neil Heron. neilheron25@yahoo.co.uk

Received: 3 February 2020; Accepted: 8 June 2020; Published: 30 June 2020

\begin{abstract}
Sports-related concussion (SRC) is a common injury within elite road cycling and SRC is typically assessed and managed with a SCAT5. However the SCAT5 cannot be applied to road cycling in its current format and the cycling community therefore need to consider modifications or indeed alternatives to the SCAT5 to allow adequate assessment and management of SRC within road cycling.

Potential solutions to consider to improve SRC assessment and management in road cycling include: 1) a SRC consensus meeting to allow modification of the SCAT5 for road cycling; 2) rule alterations to allow 'pitch-side' SRC assessment during races; 3) epidemiological injury surveillance within road cycling to better understand the issues around SRC; and, 4) better use of technologies to help diagnose SRC. We hope that these solutions can go some way to bridging the gap between SRC assessment and management between our own sport of road cycling and those with maturing SRC protocols, such as rugby union.
\end{abstract}

Keywords: sports-related concussion (SRC), concussion, road-cycling, assessment protocol, consensus meeting.

\section{Introduction}

Sports-related concussion (SRC) is an injury commonly seen within sport and is becoming a growing concern within public health [1]. The SCAT5 tool [2] and head injury assessment protocols [3] are advocated for diagnosis and management of suspected SRC but unfortunately road cycling does not have a sport-specific SRC diagnosis and management protocol. Such protocols would allow health professionals working within road cycling to optimise care of their athletes with suspected SRC.

\section{Epidemiology of SRC in road cycling}

Uncovering the actual number of cases of SRC in road cycling is challenging. However a recent study in the USA found cycling to account for $40,424(19.45 \%)$ of cases of SRC after reviewing emergency department attendees, the highest number in any sport [4]. Other studies have estimated that SRC accounts for between 7.8$9.1 \%$ of all injuries during cycling events in noncompetitive road cyclists [5]. A prospective study of SRC epidemiology in professional road cycling has not yet been completed. 


\section{How do we assess SRC in road cycling?}

The 5th Concussion Consensus Conference in Berlin (2017) produced SCAT5 [2], for healthcare professionals to acutely assess for SRC. However although the SCAT5 has been well developed for use in sports such as soccer, rugby and AFL, SCAT5 cannot be applied to road cycling in its current format due to the unique characteristics of this sport. Some of the unique demands faced by medical professionals working within road cycling include the distance between the medical team and the rider, lack of appropriate television coverage of the incident, the speed at which riders travel with little protective equipment and the fact that if the cyclist stops after an injury for medical treatment, then they are essentially removing themselves from the race due to the pace which the peloton races at. Indeed the media has unfortunately highlighted some high-profile cases of professional road cyclists with suspected SRC who are not withdrawn from the race for assessment [6], with road cycling medical team staff highlighting the dilemmas in diagnosing and managing suspected SRC in this fast-moving sport [7]. These cases have highlighted the lack of a sport-specific SRC assessment protocol in road cycling.

\section{What does the literature say?}

Despite the recognised morbidity burden associated with SRC within road cycling and the popularity of cycling as a recreational sport globally, there is a lack of literature regarding the diagnosis and management of the pathology in road cycling, with only two cases in the literature identified from a recent systematic literature review [8]. The American Cycling Association [9] have produced some limited SRC guidelines, however these are largely based on the out-dated SCAT2, originally published in 2008 [8], and thus require updating.

\section{How can we improve SRC assessment in road cycling?}

We believe that road cycling can improve SRC assessment and diagnosis through four simple solutions.

\section{1) Solution One - SRC road cycling specific consensus meeting}

The UCI medical guidelines currently advocate a multi-modal assessment in suspected SRC and the need for immediate withdrawal from the race if SRC is suspected. However no multiprofessional, internationally agreed SRC assessment protocol for road cycling has been published. The UCI medical guidelines also currently advise the use of SCAT5 for concussion assessment but this tool requires modifications for use in road cycling. In particular, the Maddock's questions are not suitable for use within road cycling. We would therefore call on the UCI to organise a SRC consensus meeting in road cycling, bringing together individual national cycling federations and medical departments of professional cycling teams. This international, multi-professional, multi-team consensus meeting should establish SRC diagnosis and management protocols for use in road cycling, helping to ensure safe cycling, from elite road races to recreational cycling.

\section{2) Solution Two - Rule Changes to allow 'pitch- side' SRC assessment}

A unique aspect of road cycling compared to other sports is that if participants are temporarily withdrawn from a race for a head injury assessment, then the rider will lose his/her position within the race whilst this assessment is on going. This medical assessment for SRC would then negatively impact on the rider's potential result and performance and riders would be reluctant to undergo this assessment for this reason. A solution to this issue could be potential rule changes within the sport, supported by the governing body, the UCI, facilitating a road side medical assessment, similar to the Head Injury Assessment (HIA) 
protocol used in rugby [11]. If the cyclist then passed this assessment, they could then be motopaced back into the position in the race which they had prior to the suspected injury. The rider would then continue to be monitored by the medical team to detect any evolving symptoms of suspected SRC, including a repeated concussion assessment on the same day of the injury following the completion of the race and the day following the injury, similar to other sports [13].

\section{3) Solution Three - Epidemiological injury surveillance within road cycling}

Road cycling does not have basic epidemiological surveillance mechanisms seen in other comparable sports at elite and recreational levels. One way to overcome this, is to establish central injury databases, as advocated by previous authors [12], particularly monitoring the riders during the 3 longest multistage races in professional road cycling (the Giro D'Italia, Tour de France and la Vuelta). These injury databases would then allow the health professionals working in professional road cycling to gain a better understanding of the patterns of SRC injuries, allowing medical teams to develop SRC prevention and improved SRC management protocols.

\section{4) Solution Four - Use of Simple Technologies}

We recognise that sports who are currently leading on SRC management are played in comparatively closed environments compared to road cycling and these sports often have a multitude of camera angles that can be used to follow general play and individual players. This real-time data can be followed live and reviewed visually using innovative approaches like the myplayXplay concussion spotting system used by the RFU [10]. However use of other forms of wearable technology that detect a fall, such as simple accelerometers, could be useful to mitigate against the lack of direct vision on all riders during competition and give a real time indication when a fall occurs, an indication of severity and thus when a SRC assessment should take place.

\section{Conclusion}

We hope that these solutions can go some way to bridging the gap between SRC assessment and management between our own sport of road cycling and those with maturing SRC protocols, such as rugby union. Further work, particularly a SRC cycling specific consensus meeting, is required to build on the existing protocols for managing SRC generally in sport and to adapt these to the unique demands in the sport of road cycling, facilitating safer participation in road cycling for all. We therefore call on the UCI, as the governing body of road cycling, to organise an appropriate multi-disciplinary consensus meeting to establish SRC diagnosis and management protocols.

\section{References}

1. Bcbs.com. (2016). The steep rise in concussion diagnoses in the U.S. I Blue Cross Blue Shield. [online] Available at: https://www.bcbs.com/the-health-ofamerica/reports/the-steep-rise-concussiondiagnoses-the-us [Accessed 26 Nov. 2018].

2. Echemendia. RJ, Meeuwisse W, McCrory P, Davis G, Putukian M, Leddy J, et al. The Sport Concussion Assessment Tool 5th Edition (SCAT5): Background and rationale. British Journal of Sport Medicine 2017;51(11):848-850.

3. Ellenbogen $\mathrm{R}$, Batjer $\mathrm{H}$, Cardenas J, Berger $\mathrm{M}$, Bailes J, Pieroth E, et al. National Football League Head, Neck and Spine Committee's Concussion Diagnosis and Management Protocol: 2017-18 season.. British Journal of Sports Medicine 2018;52(14):894-902.

4. Nonfatal Traumatic Brain Injuries From Sports and Recreation Activities-United States, 20012005. (2007). JAMA, 298(11), p.1271.

5. Decock, M., De Wilde, L., Vanden Bossche, L., Steyaert, A. and Van Tongel, A. (2016). Incidence and aetiology of acute injuries during competitive road cycling. British Journal of Sports Medicine, 50(11), pp.669-672.

6. Hutchinson J. California bleeding. Shocking moment 50mph cyclist crashes out of Tour of California....then is nearly mowed down by rivals. The Sun 2017. 
7. Beaudin M. The Inside Story of How Cannondale Reacted to Toms Skujins' Tour of California Crash. Bicycling 2017; May.

8. Elliott J, Anderson R, Collins S, et al. Sportsrelated concussion (SRC) assessment in road cycling: a systematic review and call to action. BMJ Open Sport \& Exercise Medicine 2019;5:e000525. doi: 10.1136/bmjsem-2019 000525

9. Abramson, A. (2012). Concussions in Cyclists for Team Managers and Coaches. [online] Available at: https://www.usacycling.org/getinvolved/support-

role/coaches/resources/concussionmanagement [Accessed 17 Nov. 2018].

10. Premiership Rugby. (2018). Concussion management boosted by ground-breaking new system. [online] Available at: https://www.premiershiprugby.com/news/co ncussion-management-boosted-groundbreaking-new-system/ [Accessed 26 Nov. 2018].

11. Fuller G, Kemp S, Decq P. The International Rugby Board (IRB) Pitch Side Concussion Assessment trial: a pilot test accuracy study. British Journal of Sports Medicine 2015;49(8):52935.

12. Cross M, Kemp S, Smith A, et al. Professional rugby union players have a $60 \%$ greater risk of time loss injury after concussion: a 2-season prospective study of clinical outcomes. $\mathrm{Br} \mathrm{J}$ Sports Med 2016;50:926-31.

13. Raftery 1, M; Kemp 2, S; Patricios 3, J; Makdissi 4, M; Decq, P. It Is Time to Give Concussion an Operational Definition: A 3-step Process to Diagnose (Or Rule Out) Concussion Within $48 \mathrm{H}$ of Injury: World Rugby Guideline. British Journal of Sport and Exercise Medicine. 2016 Jun;50(11):642-3. doi: 10.1136/bjsports-2016095959. Epub 2016 Mar 3. 